Analitika: Jurnal Magister Psikologi UMA, Vol. 12 (1) Juni (2020)

ISSN: 2085-6601 (Print), ISSN: 2502-4590 (Online)

DOI: http://dx.doi.org/analitika.v11i1.2815

ANALITIKA

Jurnal Magister Psikologi UMA

Available online http://ojs.uma.ac.id/index.php/analitika

\title{
Kontribusi Identitas Budaya Jawa yang Dimediasi oleh Cognitive Reappraisal dalam Membentuk Resiliensi Keluarga pada Keluarga Suku Jawa
}

\section{Contribution of Javanese Cultural Identity Mediated by Cognitive Reappraisal in Establishing Family Resilience in Javanese Families}

\author{
Lely Nur Azizah, Sri Redatin Retno Pudjiati* \\ Program Studi Psikologi Perkembangan, Fakultas Psikologi, Universitas Indonesia, Indonesia
}

Diterima: 17 Agustus 2019, disetujui: 8 Juni 2020, dipublish: 30 Juni 2020

*Corresponding author: E-mail: retno-pj@ui.ac.id

\begin{abstract}
Abstrak
Penelitian ini mencoba menggali faktor protektif resiliensi keluarga dari hal yang paling dekat dengan kehidupan individu, yaitu budaya. Penelitian ini bertujuan untuk melihat apakah identitas budaya Jawa berkontribusi pada internalisasi cognitive reappraisal dalam membentuk resiliensi keluarga pada keluarga suku Jawa. Responden penelitian terdiri dari 317 orang tua, bersuku Jawa, laki-laki (35\%) dan perempuan (65\%), berusia 25-63 tahun (M= 44, SD=7.1) yang diperoleh melalui tehnik convenience sampling. Pengambilan data dilakukan dengan metode survey menggunakan tiga alat ukur, yaitu Walsh Family Resilience Questionare ( $\alpha=0.917$ ), Dimensi cognitive reappraisal dari Emotion regulation Questionnaire $(\alpha=0.793)$, dan Alat Ukur Identitas Budaya Jawa $(\alpha=0.818)$. Analisis regresi dan uji mediasi dilakukan dengan bantuan PROCESS di SPSS. Hasil penelitian melaporkan bahwa identitas budaya Jawa berkontribusi membentuk cognitive reappraisal $(R 2=0.050 ; \beta=0.229 ; p<0.001)$. Cognitive reapraissal juga dilaporkan berkontribusi membentuk resiliensi keluarga ( $R 2=0.076 ; \beta=0.281 ; p<0.001)$, namun perannya sebagai mediator tidak terkonfirmasi karena efek kontribusinya tidak cukup besar dibandingkan jika identitas budaya Jawa berkontribusi langsung pada resiliensi keluarga (coeff jalur $\mathrm{a}^{*} \mathrm{~b}=0.0569 ; \mathrm{p}<0.001$; coeff jalur $\left.c^{\prime}=0.9369 ; \mathrm{p}<0.001\right)$.
\end{abstract}

Kata kunci: Resiliensi keluarga; Identitas Budaya Jawa; Cognitive Reappraisal

\begin{abstract}
This study explores the protective factors of family resilience from something closest of an individual life, namely culture. This study aims to examine whether Javanese cultural identity contributes to the internalization of emotion regulation in establishing family resilience in Javanese families. Respondents consisted of 317 parents, Javanese, male (35\%) and female (65\%), aged 25-63 years ( $M=44, S D=7.1)$ obtained through convenience sampling techniques. Data retrieval is done by survey method using three measuring instruments, Walsh Family Resilience Questionnaire $(\alpha=0.917)$, the cognitive reappraisal dimension of the Emotion regulation Questionnaire $(\alpha=0.793)$, and Javanese Culture Identity ( $\alpha$ $=0.818)$. Regression analysis and mediation tests were carried out with the help of PROCESS at SPSS. The results reported that Javanese cultural identity contributed to cognitive reappraisal $(R 2=0.050 ; \beta=0.229 ; p<0.001)$. Cognitive reappraisal) is also contribute to forming family resilience ( $R 2=0.076 ; \beta=0.281 ; p<0.001)$, but the role as a mediator (path coefficients $a^{*} b=0.0569 ; p<0.001$ ) is not confirmed because the effect of its contribution is not large enough than the Javanese cultural identity directly contributes to family resilience (path coefficiency $a^{*} b=0.0569 ; p<0.001$; coeff path $c^{\prime}=0.9369 ; p<0.001$.
\end{abstract}

Keywords: Family resilience; Javanese Cultural Identity; Cognitive Reappraisal

How to Cite: Azizah, L.N. \& Sri, R.R.P. (2020). Kontribusi Identitas Budaya Jawa yang Dimediasi oleh Cognitive Reappraisal dalam Membentuk Resiliensi Keluarga pada Keluarga Suku Jawa. Analitika: Jurnal Magister Psikologi UMA, 12 (1): 10 - 21 


\section{PENDAHULUAN}

Masalah yang setiap hari dialami oleh keluarga, seperti stres pengasuhan, konflik dengan pasangan, tetangga atau keluarga besar, masalah finansial dan lain sebagainya, dapat menjadi ancaman bagi kestabilan dan keutuhan keluarga (Elvika, 2019; Kristiyani, V., \& Pudjiati, 2019; Walsh, 2016). Tingginya angka perceraian di Indonesia merupakan salah satu indikator ketidakmampuan keluarga dalam menjaga kestabilan dan keutuhan keluarga. (Badan Pusat Statistik, 2019) melaporkan kenaikan angka perceraian selama tiga tahun berturut-turut, dari 365.654 kasus perceraian pada tahun 2016, kemudian naik menjadi 374.516 pada tahun 2017 dan menjadi 408.202 pada tahun 2018.

Banyaknya masalah yang dihadapai keluarga dapat menjadi faktor risiko yang melemahkan kualitas ketahanan keluarga. Namun, bagi sebagian keluarga, masalah dapat menjadi momentum titik balik yang memperkuat kualitas ketahanannya (Walsh, 2016). Melalui masalah-masalah yang dihadapinya, keluarga (sebagai sebuah sistem) berdinamika untuk menemukan solusi. Keluarga yang mampu menemukan solusi dan bangkit menjadi lebih kuat dari setiap masalah yang dihadapinya disebut sebagai keluarga yang resilien. Keluarga yang resilien dicirikan dengan kemampuannya untuk mengakses atau memanfaatkan faktor-faktor protektif yang dapat membantu mereka untuk bangkit dan menjadi lebih kuat setelah menghadapi masalah (Henry, C.S., Moris, A.S., \& Harrist, 2015)

Secara umum, terdapat tiga jenis faktor protektif yang dapat diakses oleh keluarga. Pertama, faktor individu. Individu yang kuat dan stabil (memiliki strategi regulasi emosi, coping, efikasi diri, kualitas kesehatan dan pendidikan yang baik) menjadi dasar terbentuknya keluarga yang kuat dan resilien. Kedua, faktor keluarga. Karakteristik keluarga yang kuat (pendapatan keluarga yang stabil, kestabilan hubungan suami-istri dan anak-anak serta dukungan sosial yang memadai) dapat mendukung proses adaptasi keluarga terhadap berbagai masalah. Ketiga, faktor komunitas atau lingkungan tempat keluarga tersebut tumbuh dan berkembang, termasuk di dalamnya adalah lingkungan fisik dan nilai-nilai budaya (Benzies, K., \& Myschasiuk, 2009). Penelitian telah dilakukan untuk menguji faktor protektif tersebut, dan hasilnya dilaporkan masih inkonsisten hingga saat ini. Inkonsistensi tersebut diguga karena keluarga (sebagai unit analisis) berada dalam sebuah sistem yang kompleks dan dinamis (Benzies, K., \& Myschasiuk, 2009). Sehingga, menilai konteks tempat keluarga tersebut tinggal merupakan suatu langkah yang penting (Hawley, D.R., \& DeHann, 1996; Little, M., Axford, N., \& Morpeth, 2004).

Kompleksitas konteks sosial telah lama diterangkan oleh Bronfenbrenner (1979) dalam teori ekologi. Teori ini menitikberatkan pada setting tempat individu berkembang. Latar belakang budaya, sebagai salah satu setting sosial, dipercaya sebagai salah satu sistem yang saling berpengaruh satu dengan lainnya (budaya memengaruhi segala aspek yang ada di dalamnya, baik individu, keluarga dan masyarakat, begitu juga sebaliknya).

Penelitian yang melibatkan budaya sebagai konteks penelitian telah 
dilakukan di beberapa negara, salah satunya adalah penelitian yang dilakukan di Korea Selatan. Hasil penelitian tersebut melaporkan bahwa pemahaman keluarga mengenai konsep resiliensi menentukan bagaimana keluarga tersebut mengatasi stres mereka (Lee, I., Lee, E-O., Kim, H.S., Park, Y.S., Song, M., \& Park, 2003).

Penelitian lintas budaya pun telah dilakukan dengan membandingkan bagaimana resiliensi orang-orang di barat dan di China. Hasil penelitian tersebut melaporkan adanya perbedaan faktor protektif yang penting pada masingmasing budaya. Resiliensi di negaranegara barat dipengaruhi oleh faktor protektif yang berasal dari keluarga, sedangkan faktor protektif yang penting di negara China adalah faktor protektif yang berasal dari komunitas (Wang, P., Liu, D-Z., \& Zhao, 2014).

Di Indonesia, penelitian resiliensi keluarga yang dilihat dalam konteks budaya masih sangat terbatas. Salah satu penelitian yang telah dilakukan adalah penelitian resiliensi keluarga pada suku Batak Toba (Pudjiati, 2016). Hasil penelitian tersebut melaporkan bahwa identitas budaya memengaruhi resiliensi keluarga melalui perantara dukungan komunitas.

Mengingat besarnya pengaruh nilai budaya dalam membentuk pola pikir dan perilaku seseorang, maka memahami nilai-nilai budaya tempat dimana keluarga tumbuh dan berkembang menjadi sangat penting untuk menentukan faktor protektif yang dapat berkontribusi terhadap resiliensi keluarga dalam budaya tersebut. Jika identitas budaya menjadi faktor protektif yang penting dalam kontribusinya terhadap resiliensi keluarga melalui perantara dukungan komunitas pada suku Batak Toba (Pudjiati, 2016), model ini bisa menjadi sangat berbeda jika diterapkan dalam konteks budaya lain. Hal ini disebabkan oleh perbedaan falsafah dan nilai hidup yang khas pada masing-masing budaya. Perbedaan tersebut memberikan peluang penelitian baru pada budaya lain yang memiliki nilai budaya yang berbeda, salah satunya adalah suku Jawa, yang dilaporkan memiliki angka perceraian tertinggi di Indonesia pada setiap tahunnya (BPS, 2019). Sehingga, penelitian ini diharapkan mampu memberikan solusi teoritis dari tingginya angka perceraian pada suku Jawa. Untuk menemukan model resiliensi keluarga pada suku Jawa, peneliti mencoba menggali faktor protektif terdekat yang mampu diakses oleh keluarga. Faktor tersebut adalah identitas budaya yang dinamika kontribusinya sangat bergantung pada nilai-nilai yang diterapkan dalam budaya tersebut.

Terdapat dua nilai yang menjadi cita-cita hidup orang Jawa, yaitu kerukunan dan kehormatan. Kedua nilai ini dijadikan pedoman hidup masyarakat Jawa dalam mengembangkan sikap dan perilaku (Magnis-Suseno, 1984). Nilai pertama adalah kerukunan. Kerukunan sering dimaknai sebagai keadaan damai, harmonis dan selaras. Berperilaku rukun berarti berusaha bersikap tenang dan menghindari perselisihan atau konflik. Konflik biasanya muncul akibat adanya kepentingan yang berseberangan, dalam kondisi seperti ini bertindak rukun berarti bersedia mengalah demi terciptanya kesepakatan bersama. Terdapat wisdom yang berkembang 
dalam masyarakat Jawa terkait dengan hal ini, yaitu "ngalah ora berarti kalah", yang artinya "mengalah tidak berarti kalah". Masyarakat Jawa percaya bahwa dengan mengalah, sesungguhnya seseorang dapat menjadi lebih terhormat dan menjadi lebih mulia (Magnis-Suseno, 1984).

Nilai kedua adalah kehormatan. Nilai ini memainkan peran dalam mengatur pola interaksi dalam masyarakat melalui sistem tata krama dan bahasa. Nilai kehormatan tercermin melalui bahasa dan sopan santun yang ditunjukkan ketika berinteraksi dengan orang lain. Poin penting dalam hal ini adalah menyadari kedudukan individu dalam tatanan sosial dan mampu menggunakan sikap dan bahasa yang tepat sesuai dengan kedudukannya. Sistem tata krama ini disebut masyarakat Jawa sebagai "unggah-ungguh" yang berisikan serangkaian aturan berperilaku dan berbahasa yang dinilai pantas. Beberapa wisdom, seperti sungkan (merasa tidak enak) dan isin (malu) berkembang menjadi kebiasaan yang dipraktekkan dalam masyarakat Jawa guna menunjukkan sikap hormat (Ayatrohaedi, W. S., Manan, F. N., Utomo, S. S., Sastrosuwondo, 1989; Magnis-Suseno, 1984). Internalisasi dua nilai tersebut (rukun dan hormat) memengaruhi sikap orang Jawa dalam menghadapi masalah sehari-hari. Ketika menghadapi masalah, orang jawa akan berusaha untuk menyelesaikan masalahnya secara internal dan sedapat mungkin masalah tersebut tidak menyebar diluar keluarga inti. Orang Jawa akan merasa malu (isin) jika masalah keluarganya sampai didengar oleh orang lain, hal ini berkaitan dengan harga diri dan kehormatan keluarga. Kehormatan, dalam masyarakat Jawa, diperoleh ketika seseorang mampu bersikap bijaksana dalam menghadapi masalah hidup. Sikap bijaksana dalam masyarakat Jawa sering dikaitkan dengan sikap berhati-hati (berpikir sebelum bertindak). Sikap tersebut disosialisasikan melalui wisdom seperti wawas diri (instropeksi diri), nastiti lan ngati-ati (cermat dan berhati-hati), dan aja dumeh (jangan mentang-mentang) (Besar, 2010; Budiyono, B., \& Feriandi, 2017). Selain itu, dalam menghadapi masalah, orang Jawa dibiasakan untuk senantiasa bersikap tenang dengan cara bersabar, ikhlas, nrima dan legawa (menerima segala kondisi sebagai ketetapan dari Tuhan dengan lapang dada) (Ayatrohaedi, W. S., Manan, F. N., Utomo, S. S., Sastrosuwondo, 1989; Magnis-Suseno, 1984).

Pembiasaan dan internalisasi nilainilai budaya yang senantiasa disosialisasikan oleh masyarakat Jawa terkait dengan sikap tenang dan berhatihati memengaruhi strategi seseorang dalam meregulasi emosinya. Strategi regulasi emosi yang sering dikaitkan dengan aktivitas kognitif (berpikir sebelum bertindak) adalah strategi cognitive reappraisal. Cognitive reappraisal merupakan strategi regulasi emosi yang menekankan pada penilaian kembali sumber emosi negatif untuk menentukan tindakan apa yang akan ditampilkan oleh individu setelahnya. Dalam menjalankan cognitive reappraisal, dibutuhkan sumber kognitif yang memadai untuk menilai dan mengevaluasi kembali berbagai stimulus yang berpotensi dipandang sebagai masalah. 
Nilai-nilai budaya, falsafah hidup dan wisdom yang diinternalisasi oleh individu merupakan salah satu sumber kognitif yang dapat diakses oleh individu kapan saja saat dibutuhkan (Gross, J. J., \& John, 2003; Holodynski, F. \& Friedlmeier, 2005).

Cognitive reappraisal, yang selalu dipraktekkan oleh masyarakat Jawa dalam kehidupan sehari-hari, dianggap dapat membantu individu untuk lebih efektif dalam mengatasi konflik yang dihadapinya (Min, J-A., Yu, J.J., Lee, C-U., \& Chae, 2013; Poegoeh, D.P., \& Hamidah, 2016). Cognitive reappraisal dilaporkan dapat meningkatkan kualitas pribadi (self esteem dan optimisme), kualitas hubungan interpersonal, kesejahteraan psikologis (Gross, J. J., \& John, 2003) dan resiliensi keluarga (Poegoeh, D.P., \& Hamidah, 2016). Cognitive reappraisal membantu keluarga untuk dapat bersikap tenang dan berpikir jernih ketika menghadapi masalah. Hal ini dapat membantu keluarga secara efektif menemukan solusi pemecahan masalahnya.

Sehingga, berdasarkan kajian diatas, peneliti membangun tiga hipotesis. Pertama, Identitas budaya Jawa berkontribusi terhadap pembentukan cognitive reappraisal. Kedua, cognitive reappraisal berkontribusi membentuk resiliensi keluarga. Ketiga, Identitas budaya Jawa berkontribusi dalam internalisasi cognitive reappraisal yang berpengaruh dalam membentuk resiliensi keluarga.

\section{METODE PENELITIAN}

Metode penelitian yang digunakan adalah kuantitatif non eskperimental.
Pengambilan data dilakukan dengan metode survey dengan teknik convenience sampling. Sebelum penelitian dimulai, Komite Etika Penelitian Fakultas Psikologi Universitas Indonesia telah menyetujui seluruh prosedur pelaksanaan penelitian. Penelitian ini telah dinyatakan memenuhi standar etis disiplin ilmu psikologi dan kode etik riset Universitas Indonesia.

Penelitian ini melibatkan 317 orang tua, responden diperoleh melalui survei yang disebar secara daring (24\%) dan luring (76\%). Responden penelitian merupakan orang tua bersuku Jawa, berjenis kelamin laki-laki (35\%) dan perempuan (65\%), berusia 25-63 tahun $(\mathrm{M}=44, \mathrm{SD}=7.1)$ dengan jumlah anak 1 sebesar 18\%, 2 anak sebesar 46\%, 3 anak sebesar 20\%, dan lebih dari 3 anak sebesar $16 \%$. Tiga puluh satu persen responden bekerja sebagai wiraswasta, $19 \%$ sebagai petani, $16 \%$ sebagai Guru/Dosen, $14 \%$ sebagai PNS, 12\% sebagai karyawan swasta, $7 \%$ sebagai kuli, dan $1 \%$ pensiunan TNI. Tingkat pendidikan responden tersebar mulai dari SD sebesar 13\%, SMP sebesar 15\%, SMA sebesar $30 \%$, diploma sebesar $2 \%$, sarjana sebesar 28\% dan pascasarjana sebesar 11\%. Empat puluh tiga persen responden berstatus sosial ekonomi menengah, $32 \%$ rendah dan $25 \%$ tinggi.

Pengukuran dilakukan dengan metode self report. Variabel resiliensi keluarga diukur dengan Walsh Family Resilience Questionare (WFRQ) yang telah diadaptasi oleh Pudjiati (2016) ( $\alpha=$ 0.917). Alat ukur ini berisi 36 aitem yang bersifat close ended. Jawaban responden diberikan skor 1 (sangat tidak sesuai) sampai 4 (sangat sesuai). Skor total yang 
diperoleh menggambarkan kondisi resiliensi keluarga. Semakin tinggi skor, maka semakin tinggi tingkat resiliensi keluarga.

Identitas budaya Jawa diukur dengan alat ukur yang dikembangkan oleh Kristiyani dan Pudjiati (2019) ( $\alpha=$ 0.818). Alat ukur ini terdiri dari 21 aitem skala likert (19 aitem favourable dan 2 aitem unfavourable). Terdapat empat pilihan jawaban dari sangat tidak setuju (skor 1 untuk aitem favourable dan skor 4 untuk aitem unfavourable) sampai sangat setuju (skor 4 untuk aitem favourable dan skor 1 untuk aitem unfavourable). Total skor yang diperoleh merepresentasikan tingkat identitas budaya Jawa, semakin tinggi skor yang diperoleh semakin tinggi tingkat identitas budaya Jawa responden.

Cognitive reappraisal diukur dengan dimensi Cognitive reappraisal dari Emotion Regulation Questionnaire (ERQ) yang telah diadaptasi oleh Ratnasari dan Suleeman (2017). Cognitive reappraisal terdiri dari 6 aitem $(\alpha=$ 0.793). Masing-masing aitem memuat jawaban dengan rentang 1 (sangat tidak setuju) sampai 7 (sangat setuju). Skor total menggambarkan seberapa tinggi tingkat cognitive reappraisal individu, semakin tinggi skor total maka semakin tinggi tingkat cognitive reappraisal responden.

Data dari ketiga alat ukur di atas dianalisis menggunakan analisis regresi dan uji mediasi menggunakan PROCESS di SPSS. Teknik analisis data ini digunakan untuk melihat kontribusi identitas budaya Jawa terhadap resiliensi keluarga yang dimediasi oleh cognitive reappraisal.

\section{HASIL DAN PEMBAHASAN}

Hasil analisis deskriptif (lihat Tabel 1) melaporkan bahwa responden memiliki tingkat resiliensi keluarga yang tinggi dan sedang. Hal ini sejalan dengan tingkat identitas budaya Jawa yang secara umum berada dalam kategori tinggi dan tingkat cognitive reappraisal yang secara umum berada dalam kategori sedang dan tinggi.

Tabel 1. Hasil Analisis Deskriptif

\begin{tabular}{lccccc}
\hline \multicolumn{1}{c}{ Variabel } & $\mathrm{M}$ & $\mathrm{SD}$ & \multicolumn{3}{c}{ Kategori } \\
\cline { 3 - 6 } & & & $\mathrm{T}$ & $\mathrm{S}$ & $\mathrm{R}$ \\
\hline $\begin{array}{l}\text { Resiliensi } \\
\text { Keluarga }\end{array}$ & 90 & 18 & $57 \%$ & $43 \%$ & $\mathrm{0} \%$ \\
\hline $\begin{array}{l}\text { Identitas } \\
\text { Budaya Jawa }\end{array}$ & 52.5 & 10.5 & $74 \%$ & $26 \%$ & $\mathrm{0} \%$ \\
\hline $\begin{array}{l}\text { Cognitive } \\
\text { Reapraissal }\end{array}$ & 24 & 6 & $40 \%$ & $56 \%$ & $4 \%$ \\
\hline
\end{tabular}

Hasil analisis regresi menjawab hipotesis pertama dan kedua. Hipotesis pertama dalam penelitian ini diterima. Identitas budaya Jawa dilaporkan berkontribusi secara positif terhadap pembentukan cognitive reappraisal (lihat tabel 2; R2=0.050; $\beta=0.229 ; \mathrm{p}<0.001$ ) dengan besar kontribusi sebesar 5\%, artinya kenaikan skor pada identitas budaya Jawa akan diiringi dengan kenaikan skor pada cognitive reappraisal dengan perubahan sebesar 5\%.

Temuan ini sejalan dengan teori yang menyatakan bahwa cognitive reappraisal dipengaruhi oleh faktor budaya. Identitas budaya Jawa memengaruhi cognitive reappraisal melalui sosialisasi nilai-nilai budaya dalam masyarakat (Gross, 2015; Holodynski, F. \& Friedlmeier, 2005). Nilai-nilai tersebut menjadi sumber kognitif yang penting bagi individu untuk melakukan penilaian ulang terhadap 
situasi dan pengalaman tidak menyenangkan (cognitive reappraisal) dalam menghadapi masalah.

Ketika menghadapi masalah, orang jawa akan berusaha untuk tetap bersikap tenang dengan cara bersabar, ikhlas, ngalah, nrima dan legawa. Untuk mencapai derajat legawa (menerima dengan lapang dada), orang Jawa melakukan cognitive reappraisal dengan menggunakan berbagai sumber kognitif yang dimilikinya. Sumber kognitif yang diperoleh melalui internalisasi nilai-nilai budaya digunakan orang jawa untuk menimbang dan memikirkan kembali segala peristiwa negatif sebagai sebuah takdir atau ujian dari Tuhan yang harus dihadapi dengan pandangan positif.

Namun, besar kontribusi identitas budaya Jawa dalam membentuk cognitive reappraisal hanya sebesar 5\%, artinya terdapat $95 \%$ faktor lain yang turut memengaruhi terbentuknya cognitive reappraisal. Secara teoritis, faktor lain yang mungkin memengaruhi pembentukan cognitive reappraisal adalah usia, gender, keluarga (termasuk pengasuhan), lingkungan dan tingkat pendidikan (Holodynski, F. \& Friedlmeier, 2005; Ratnasari, S., \& Suleeman, 2017).

Selanjutnya, hipotesis kedua dalam penelitian ini diterima, yaitu cognitive reappraisal berkontribusi secara positif membentuk resiliensi keluarga (lihat tabel 2; R2=0.076; $\beta=$ $0.281 ; \quad \mathrm{p}<0.001$ ) dengan kontribusi sebesar 7.6\%, artinya kenaikan skor pada cognitive reappraisal akan diiringi dengan kenaikan skor pada resiliensi keluarga dengan perbedaan sebesar 7.6\%. Hal ini sejalan dengan hasil temuan yang menyatakan bahwa cognitive reappraisal dapat meningkatkan resiliensi keluarga pada keluarga penderita skizofrenia (Poegoeh, D.P., \& Hamidah, 2016).

Sementara itu, cognitive reappraisal, dalam banyak penelitian juga dilaporkan berkontribusi pada peningkatan kualitas pribadi individu secara positif, seperti meningkatkan kebahagian, kepuasan hidup, self esteem, optimisme, dan meningkatkan kualitas hubungan interpersonal. Penggunaan cognitive reappraisal juga berkorelasi dengan sedikitnya gejala depresi dan gejala anxiety pada individu (Betts, J., Gullone, E., \& Allen, 2009; Gross, J. J., \& John, 2003; Hughes, E. K., Gullone, E., Dudley, A., \& Tonge, 2010).

Hal tersebut sejalan dengan pendapat Benzies, K., \& Myschasiuk, (2009) yang menyatakan bahwa kualitas individu yang positif dan bahagia merupakan salah satu faktor kunci dari terbentuknya resiliensi keluarga. Sehingga, semakin baik kualitas pribadi individu akan diringi dengan peningkatan kualitas resiliensi keluarganya.

Namun, kontribusi cognitive reappraisal dalam meningkatkan resiliensi keluarga hanya sebesar $7.6 \%$, artinya terdapat $92.4 \%$ kontribusi dari faktor lain yang turut memengaruhi terbentuknya resiliensi keluarga. Faktor lain yang diperkirakan dapat meningkatkan resiliensi keluarga oleh Benzies, K., \& Myschasiuk (2009) disebut sebagai faktor protektif. Paling tidak terdapat tiga sumber faktor protektif yang dapat diakses keluarga, yaitu faktor individu (efikasi diri, coping, locus of 
control internal, sistem kepercayaan, pendidikan, kesehatan, temperament, dan gender), faktor keluarga (struktur keluarga, stabilitas hubungan pasangan suami-istri, family cohesion, interaksi yang saling mendukung antara orang tua dan anak, dukungan sosial, kestabilan keuangan, perumahan yang memadai), dan faktor masyarakat atau lingkungan (perawatan kesehatan yang berkualitas, akses terhadap sekolah, lingkungan yang aman, tempat pengasuhan anak yang memadai, penerimaan dari teman sebaya atau masyarakat, keterlibatan dalam komunitas).

Tabel 2. Hasil Analisis Regresi

\begin{tabular}{lcc}
\hline Variabel & \multicolumn{2}{c}{ Adjusted $\mathrm{R}^{2} /$ Standardized Beta $(\beta)$} \\
\cline { 2 - 3 } Penelitian & $\mathrm{RK}$ & $\mathrm{IBJ}$ \\
\hline $\mathrm{IBJ}$ & $0.360^{* * *} / 0.602^{* * *}$ \\
\hline$C R$ & $0.076^{* * *} / 0.281^{* * *}$ & $0.050^{* * *} / 0.229^{* * *}$ \\
\hline${ }^{*} \mathrm{p}<0.05 ;{ }^{* *} \mathrm{p}<0.01 ;{ }^{* * *} \mathrm{p}<0.001$
\end{tabular}

Note: IBJ= Identitas Budaya Jawa; $\mathrm{CR}=$ Cognitive reappraisal; $\mathrm{RK}=$ Resiliensi Keluarga

Selanjutnya, uji mediasi dilakukan untuk menjawab hipotesis penelitian ketiga. Hasil analisis mediasi menyatakan bahwa hipotesis penelitian ketiga ditolak. Untuk memahami dinamika mediasi regulasi emosi, dapat dilihat pada diagram 1. Pada diagram 1, dilaporkan semua jalur memiliki signifikansi yang baik (jalur a merupakan hubungan antara identitas budaya Jawa dengan cognitive reappraisal, coeff $=0.2273, \mathrm{p}<0.001$; jalur b merupakan hubungan antara cognitive reappraisal dengan resiliensi keluarga, coeff $=0.2505, \quad \mathrm{p}<0.001 ;$ jalur $\quad \mathrm{c}^{\prime}$ merupakan hubungan langsung antara identitas budaya Jawa dengan resiliensi keluarga, coeff $=0.9369, \quad \mathrm{p}<0.001)$, artinya semua jalur memiliki hubungan yang signifikan. Hubungan yang signifikan pada jalur a bermakna bahwa identitas budaya Jawa benar-benar berkontribusi meningkatkan cognitive reappraisal. Jalur b bermakna bahwa cognitive reappraisal terbukti berkontribusi meningkatkan resiliensi keluarga. Jalur c' bermakna bahwa identitas budaya Jawa terkonfirmasi berkontribusi langsung dalam meningkatkan resiliensi keluarga.

Pada diagram 1 terlihat bahwa cognitive reappraissal tidak memainkan perannya sebagai mediator (jalur $\mathrm{a}^{*} \mathrm{~b}=$ $\left.0.2273^{*} 0.2505=0.0569\right)$ karena efek kontribusinya tidak cukup besar dibandingkan jika identitas budaya Jawa berkontribusi langsung pada resiliensi keluarga (jalur c'=0.9369). Dari model tersebut diketahui bahwa besar pengaruh kontribusi identitas budaya Jawa akan semakin besar jika berhubungan langsung dengan resiliensi keluarga. Mediasi cognitive reappraisal dalam model ini justru menurunkan angka kontribusi identitas budaya Jawa dalam meningkatkan resiliensi keluarga.

Diagram 1. Model Mediasi Cognitive Reappraisal terhadap kontribusi identitas budaya Jawa pada pembentukan resiliensi keluarga

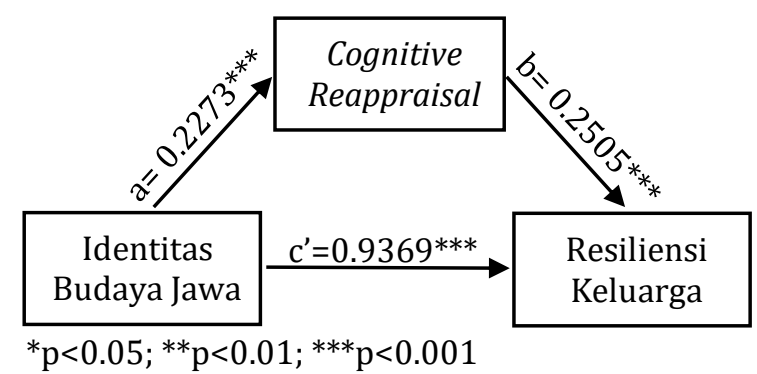

Temuan ini sejalan dengan hasil penelitian yang dilakukan oleh Elvika (2019) yang melaporkan bahwa identitas 
budaya berkontribusi secara langsung pada resiliensi keluarga di budaya Minangkabau. Identitas budaya juga dilaporkan memiliki kontribusi langsung dengan resiliensi di budaya barat (Weaver, 2009). Namun, hasil penelitian ini tidak sejalan dengan hasil penelitian yang dilakukan oleh Pudjiati (2016) di budaya Batak Toba, yang mana identitas budaya tidak memiliki kontribusi langsung yang signifikan. Identitas budaya Batak Toba memiliki kontribusi yang signifikan ketika dimediasi oleh dukungan komunitas. Dukungan komunitas dalam budaya Batak Toba tersedia melalui ikatan marga yang kuat. Pudjiati (2018), dalam analisisnya, melaporkan bahwa hal pertama yang dilakukan orang Batak ketika mengalami kesulitan adalah menghubungi komunitas marganya untuk mencari alternatif solusi. Hal ini sangat bertolak belakang dengan orang Jawa. Hal pertama yang dilakukan orang Jawa ketika menghadapi masalah adalah dengan mencoba untuk bersikap tenang, tidak gegabah dan sedapat mungkin menjaga agar masalah tersebut dapat diselesaikan secara internal (MagnisSuseno, 1984; Ayatrohaedi, W. S., Manan, F. N., Utomo, S. S., Sastrosuwondo, 1989).

Secara teoritis, perbedaan model resiliensi keluarga dalam dua budaya ini dapat dijelaskan dengan teori Bronfenbrenner yang telah direvisi oleh (Velez-Agosto, N. M., Soto-Grespo, J. G., Vizcarrondo-Oppenheimer, M., VegaMolina, S \& Coll, 2017) yang menyatakan bahwa budaya merupakan determinan utama yang memengaruhi individu secara langsung. Menurutnya, budaya tidak lagi berada pada level makrosistem, namun berada pada level mikrosistem yang sangat dekat dan berpengaruh secara langsung pada perkembangan individu. Identias budaya Jawa langsung memengaruhi resiliensi keluarga melalui internalisasi nilai yang mendalam dalam diri individu. Sehingga identitas budaya dalam masyarakat Jawa masuk dalam dimensi internal yang tidak perlu dimediasi oleh faktor apapun. Cita-cita dan falsafah hidup orang Jawa untuk menjaga keselarasan dan keharmonisan yang telah diciptakan oleh Tuhan, mendorong orang-orang Jawa untuk memiliki olah batin dan penjagaan diri yang baik (Magnis-Suseno, 1984). Olah batin dan penjagaan diri merupakan faktor-faktor yang berada pada level individu yang secara langsung mampu memengaruhi resiliensi keluarga tanpa melalui perantara apapun (Benzies, K., \& Myschasiuk, 2009).

Kontribusi langsung identitas budaya Jawa juga dapat dijelaskan dengan melihat peran identitas budaya Jawa dalam memengaruhi tiga proses kunci resiliensi keluarga, yaitu sistem kepercayaan keluarga, proses komunikasi, dan proses organisasi. Pertama, nilai-nilai budaya memengaruhi sistem kepercayaan keluarga (family belief system) yang merupakan inti dari fungsi dan kekuatan keluarga "the heart and soul of resilience" (Walsh, 2016). Sistem kepercayaan keluarga menentukan bagaimana cara keluarga memaknai suatu masalah (Chen, Du, Ho, Ou, Chang \& Chen, 2017). Nilai-nilai budaya Jawa seperti sabar, syukur, ikhlas, ngalah, nrima dan legawa menuntun keluarga untuk mengembangkan pemaknaan positif pada setiap peristiwa 
kehidupan, baik menyenangkan maupun tidak. Pemaknaan positif ini mampu membantu keluarga untuk membuat keputusan dan mengambil tindakan yang efektif ketika menghadapi kesulitan, sehingga keluarga mampu dengan maksimal memanfaatkan segala faktor protektif yang dimiliki untuk menjadi resilien (Walsh, 2016).

Proses kunci yang kedua adalah proses komunikasi. Proses komunikasi yang dibangun dalam keluarga suku Jawa dipengaruhi oleh nilai-nilai budaya jawa seperti nilai rukun dan hormat. Sikap mau mengalah, menghormati segala bentuk perbedaan dan mau mengedepankan kepentingan orang lain demi terciptanya kerukunan merupakan poin penting dalam proses komunikasi yang efektif. Keterampilan komunikasi dikembangkan melalui penempatan sikap dan pemilihan bahasa yang tepat sesuai dengan kedudukannya dalam menjaga kerukunan yang telah menjadi cita-cita hidup. Etiket ini menjadi unggahungguh, serangkaian aturan perilaku dan tutur bahasa yang dinilai pantas dalam menjaga keselarasan sosial dan menghindari konflik. Orang Jawa belajar untuk berempati dengan lawan bicara, tidak menyela pembicaraan, tidak berperasangka buruk, bahkan bersikap mengalah dan menghormati perbedaan demi mengedepankan kepentingan bersama (Magnis-Suseno, 1984).

Selanjutnya, proses kunci yang ketiga adalah proses organisasi keluarga. Proses organisasi keluarga yang baik dibangun melalui tiga faktor penting, yaitu fleksibilitas dalam menghadapi perubahan (dibentuk melalui nilai ikhlas dan nrima), keterhubungan antar anggota keluarga (dibentuk melalui nilai rukun), dan ketersediaan sumber daya ekonomi dan sosial yang memadai (dibentuk melalui nilai guyub rukun dan gotong royong). Prinsip-prinsip saling menghormati dan menyadari peran serta kedudukan individu dalam keluarga mampu membantu keluarga untuk tetap menjaga stabilitas dan keharmonisan keluarga, sehingga keluarga mampu berfungsi secara optimal. Akhirnya, ketika keluarga mampu menjalankan fungsinya dengan baik, keluarga tersebut akan memiliki resiliensi yang baik (Ayatrohaedi, W. S., Manan, F. N., Utomo, S. S., Sastrosuwondo, 1989; Walsh, 2016). Selanjutnya, penelitian ini memiliki beberapa keterbatasan. Salah satunya adalah karakteristik responden yang sebagian besar berasal dari wilayah Jawa Timur dan tinggal di perdesaan. Penelitian selanjutnya dapat mempertimbangkan aspek demografi yang berbeda, seperti wilayah perkotaan atau masyarakat Jawa yang merantau, sehingga dapat diketahui apakah ada perbedaan pengaruh identitas budaya yang signifikan pada masing-masing karakteristik tersebut. Selain itu, penelitian ini melihat resiliensi keluarga dari sudut pandang atau persepsi orang tua, penelitian selanjutnya dapat mempertimbangkan persepsi resiliensi keluarga dari sudut pandang anak.

\section{SIMPULAN}

Pada penelitian ini ditemukan hasil bahwa identitas budaya Jawa secara signifikan berkontribusi terhadap pembentukan cognitive reappraisal. Selanjutnya, cognitive reappraisal secara signifikan berkontribusi dalam 
membentuk resiliensi keluarga, namun perannya sebagai mediator tidak terkonfirmasi dalam penelitian ini. Hal tersebut karena identitas budaya Jawa terbukti memberikan sumbangsih lebih besar ketika berhubungan langsung dengan resiliensi keluarga. Dengan demikian, hasil penelitian ini diharapkan mampu membuka mata masyarakat untuk lebih menyadari adanya peran budaya sebagai faktor yang dapat dimanfaatkan untuk memperoleh sumber kekuatan dalam meningkatkan resiliensi keluarga. Lebih lanjut, merawat nilai-nilai budaya atau lokal wisdom merupakan salah satu langkah yang diharapkan untuk dapat meningkatkan kualitas ketahanan keluarga Indonesia.

\section{DAFTAR PUSTAKA}

Ayatrohaedi, W. S., Manan, F. N., Utomo, S. S. Sastrosuwondo, S. (1989). Tata karma di beberapa daerah di Indonesia. Departemen Kependidikan dan Kebudayaan.

Badan Pusat Statistik. (2019). Statistik Indonesia 2019: Statistical Yearbook of Indonesia 2019. Badan Pusat Statistik.

Benzies, K., \& Myschasiuk, R. (2009). Fostering family resiliency: a review of the key protective factors. Child $\mathcal{E}$ Family Social Work, 14, 103-114.

Besar. (2010). Implementasi nilai-nilai falsafah ojo dumeh di kalangan mahasiswa universitas bina nusantara. Humaniora, 45(1), 658-667.

Betts, J., Gullone, E., \& Allen, J. S. (2009). An examination of emotion regulation, temperament, and parenting style as potential predictors of adolescent depression risk status: A correlational study. British Journal of Developmental Psychology, 27, 473-485.

Bronfenbrenner, U. (1979). The Ecology Of Human Development: Experiments by Nature and Design. Harvard University Press.

Budiyono, B., \& Feriandi, Y. A. (2017). Menggali nilai-nilai kearifan lokal budaya jawa sebagai sumber pendidikan karakter. Seminar Nasional Bimbingan Dan Konseling, 1, 92-103.

Chen, C. M., Du, B. F., Ho, C. L., Ou, W. J., Chang, Y. C., \& Chen, W. C. (2018). Perceived Stress, ParentAdolescent/Young Adult Communication, and Family Resilience among Adolescents/Young Adults Who Have a Parent with Cancer in Taiwan: A Longitudinal Study. Cancer Nursing, 41(2): 100-108.

Elvika, R. R. (2019). Stres dari gangguan seharihari sebagai prediktor dalam pembentukan resiliensi keluarga yang dimoderasi oleh peran identitas budaya pada suku Minangkabau. Universitas Indonesia.

Gross, J. J., \& John, O. P. (2003). Individual differences in two emotion regulation processes: Implications for affect, relationships, and well-being. Journal of Personality and Social Psychology, 85, 348-362.

Gross, J. J. (2015). Handbook of Emotion Regulation (second edi). The Guilford Press.

Hawley, D.R., \& DeHann, L. G. (1996). Toward a Definition of Family Resilience: Integrating Life-Span and Family Perspektives. Family Process, 35(3), 283298.

Henry, C.S., Moris, A.S., \& Harrist, A. W. (2015). Family resilience: moving into the third wave. Family Relations, Interdiciplinary Journal of Applied Family Studies, 64(1), 22-43.

https://doi.org/https://doi.org/10.1111/far e.12106

Holodynski, F. \& Friedlmeier, W. (2005). Development of Emotions and Their Regulation; An Internalization Model. Springer.

Hughes, E. K., Gullone, E., Dudley, A., \& Tonge, B. (2010). A casecontrol study of emotion regulation and school refusal in children and adolescents. 30, 691-706.

Kristiyani, V., \& Pudjiati, S. R. R. (2019). Parenting stress sebagai prediktor dalam pembentukan resiliensi keluarga yang dimoderasi oleh identitas budaya jawa. Analitika: Jurnal Magister Psikologi UMA, 11(1), 6o-71. https://doi.org/http://dx.doi.org/analitik a.v11i1.2408 
Lee, I., Lee, E-O., Kim, H.S., Park, Y.S., Song, M., \& Park, Y. H. (2003). Concept development of family resilience: a study of korean families with a chronically ill child. Journal of Clinical Nursing, 13(5), 636-645.

Little, M., Axford, N., \& Morpeth, L. (2004). Research review: risk and protection in the context of services for children in need. Child and Family Social Work, 9, 105-117.

Magnis-Suseno, F. (1984). Etika Jawa: Sebuah Analisa Falsafi tentang Kebijaksanaan Hiudp Jawa. Gramedia.

Min, J-A., Yu, J.J., Lee, C-U., \& Chae, J.-H. (2013). Cognitive emotion regulation strategies contributing to resilience in patients with depression and/or anxiety disorders. Comprehensive Psychiatry, 54, 1190-1197.

Poegoeh, D.P., \& H. (2016). Peran dukungan sosial dan regulasi emosi terhadap resiliensi keluarga penderita skizofrenia. Insan, 1(1), 12-21.

Pudjiati, S. R. R. (2016). Model resiliensi keluarga: pengaruh identitas budaya, coping, family strain, status sosial ekonomi dan dukungan komunitas dalam pembentukan resiliensi keluarga pada suku batak batak toba. Disertasi. Tidak dipublikasikan. Universitas Indonesia.

Ratnasari, S., \& Suleeman, J. (2017). Perbedaan regulasi emosi perempuan dan laki-lakidi perguruan tinggi. Jurnal Psikologi Sosial, $15(1), 35-46$.

Velez-Agosto, N. M., Soto-Grespo, J. G., Vizcarrondo-Oppenheimer, M., VegaMolina, S \& Coll, C. G. (2017). Bronfenbrenner's bioecological theory revision: moving culture from the macro into the micro. Perspectives on Psychological Science, 12(5), 900-910.

Walsh, F. (2016). Strengthening Family Resilience (Third Edit). Guilford.

Wang, P., Liu, D-Z., \& Zhao, X. (2014). The social ecology of resilience: a comparison of chinese and western researches. Procedia - Social and Behavioral Sciences, 116, 32593265.

Weaver, D. E. (2009). The Relationship between Cultural/ Ethnic Identity and Individual Protective Factors of Academic Resilience. A Dissertation. The College of William and Mary 